\title{
Knowledge and Attitudes about Dental Trauma Among the Students of the University of Split
}

\section{Znanje i stajališta među studentima Sveučilišta u Splitu o zubnoj traumi}

\author{
${ }^{1}$ Department of Dental Medicine, University Hospital Centre Zagreb, Croatia \\ Zavod za dentalnu medicinu KBC-a Zagreb, Hrvatska \\ 2 Department of Restorative Dental Medicine and Endodontics, Study of Dental Medicine, School of Medicine, University of Split, Croatia \\ Zavod za restaurativnu dentalnu medicinu i endodonciju Studija dentalne medicine, Medicinski fakultet, Sveučilište u Splitu, Hrvatska \\ ${ }^{3}$ Department of Maxillofacial Surgery, Clinical Hospital Centre Split, Croatia \\ Odjel za maksilofacijalnu kirurgiju Kliničkoga bolničkog centra Split, Hrvatska \\ ${ }^{4}$ Department of Oral and Maxillofacial Surgery, University Hospital Dubrava, School of Dental Medicine, University of Zagreb, Croatia \\ Zavod za oralnu i maksilofacijalnu kirurgiju Sveučilišne bolnice Dubrava, Stomatološki fakultet Sveučilišta u Zagrebu, Hrvatska \\ ${ }^{5}$ Department of Endodontics and Restorative Dentistry, School of Dental Medicine, University of Zagreb, Croatia \\ Zavod za endodonciju i restaurativnu stomatologiju Stomatološkog fakulteta Sveučilišta u Zagrebu, Hrvatska
}

\section{Abstract}

Objectives: Dental trauma among children is a common problem, and everyone who works with them needs to possess appropriate knowledge and skills to provide proper care at the site of the accident. The aim was to evaluate the knowledge of emergency management of dental trauma among students who should be capable of managing such injuries in their future career. Material and Methods: A cross-sectional survey regarding dental trauma emergency management was conducted on 679 students from five different studies using a questionnaire. The obtained data were analyzed by the Student t-test or one - way ANOVA using the Tukey's post-hoc test and multiple linear regression analysis $(p<0.05)$. Results: The total knowledge score regarding the emergency management of dental trauma among examined student was $4.32 \pm 2.25(\max 10)$. The positive association of the knowledge score was observed with the age of student $(\beta=0.722, p \leq 0.001)$. A similar relation was observed depending on whether they received dental injuries training during their academic education $(\beta=2.365$, $p \leq 0.001$ ), as well as students' assessment of the importance of knowledge regarding dental trauma emergency management $(\beta=0.433, p \leq 0.001)$. Conclusions: It can be concluded that the surveyed students have limited knowledge regarding dental injuries and their emergency management procedures. The obtained data emphasized the importance of additional education of all professions that may encounter dental trauma injuries to improve the outcomes of dental trauma treatment.
Received: April 30, 2020

Accepted: September 1, 2020

Address for correspondence

Antonija Tadin,

University of Split

School of Dental Medicine

Department of Restorative Dental

Medicine and Endodontics,

Šoltanska 2, 21000 Split, Croatia

ORCID ID: 0000-0002-5365-9816;

Phone: +38598609191 ,

Fax: +38521557624 ,

atadin@mefst.hr

Key words

Tooth Injuries; Emergency Treatment;

Students; Health Knowledge Attitudes Practice

\section{Introduction}

Traumatic dental injuries are a significant public health problem that can have various biological, psychosocial, emotional and economic impact on the quality of life of the affected individual (1). Injuries most often occur among preschool children, schoolchildren and young adults (2). Kindergartens, schools, playgrounds, and sports facilities are places with a high probability of the occurrence of dental trauma during children's physical activity. For these reasons, it is essential that different professional groups, including educational and health professionals, are adequately informed about this subject and, also sufficiently prepared for it (3).

Various studies have observed insufficient knowledge regarding dental injuries and their emergency treatment procedures in different professional groups who work with chil-

\section{Uvod}

Traumatske ozljede zuba velik su javnozdravstveni problem koji može imati biološke, psihosocijalne, emocionalne i ekonomske posljedice na kvalitetu života ozlijeđenog pojedinca (1). Ozljede se najččšce događaju predškolskoj djeci, onoj u školskoj dobi te mladima (2). Mjesta na kojima je velika mogućnost da će se dogoditi trauma zuba jesu dječji vrtići, škole, igrališta te sportski objekti. Iz tih je razloga bitno da su osobe različitih zanimanja, uključujući obrazovne i zdravstvene radnike, dovoljno informirane o toj temi i pripremljene da mogu pružiti pomoć (3).

Autori različitih studija uočili su nedovoljno znanje o traumatskim ozljedama zuba i postupcima hitnog liječenja u različitim profesionalnim grupama koje rade $s$ djecom, kao što su učitelji, nastavnici predškolskog odgoja, nastavnici tjele- 
dren, such as teachers, preschool teachers, physical education teachers and physicians (4-9). Similar results were obtained when medical students, physical education students and dental students were surveyed $(3,8,10,11)$.

These results are disturbing since dental traumas are considered an emergency and have to be treated immediately (10). Except for the time elapsed between the trauma episodes and the moment when the dental treatment was undertaken, first aid at the site of the accident plays a crucial role in the short-term and long-term outcome of those teeth (12). Therefore, immediate and appropriate management is required by the witnesses at the site of the accident. Besides, inadequate knowledge in providing necessary first aid can lead to irreversible damage of the tooth (crown discoloration, mobility, sensitivity, pulp necrosis, root resorption, tooth fracture, tooth loss) $(3,13)$. Following the previously mentioned, adequate knowledge of dental trauma management by these professions and by the general population is considered necessary. Additionally, it is vital to raise awareness of dental trauma emergency protocols among young people who are currently being educated for these professions. It is necessary to include dental trauma emergency protocols in their college education, thus preparing them to act when such unpredictable situations occur (3).

The objective of this study was to examine and compare the level of knowledge of students (medical and non-medical) from the University of Split regarding emergency dental trauma management. Physicians, preschool, school, and physical education teachers, due to the nature of their work, might be the first to treat dental injuries on many occasions and their reaction could determine the success and the prognosis of further treatment by the dentist. An evaluation of students' level of knowledge is essential to emphasize the need for additional educational campaigns - training courses regarding the risk of dental trauma and its management campaigns that will strengthen the knowledge of these groups, as well as confidence, and eliminate problems or doubts when handling these types of situations that can be challenging and unpleasant even for the professionals with sufficient knowledge (13-18).

\section{Material and Methods}

This cross-sectional study was conducted between May and June in 2019. A questionnaire related to dental trauma knowledge was completed by students in five different academic departments, including two health-related studies (Medicine and Dental Medicine) and three non-health-related studies (Teacher's Education, Pre-school Education, and Physical Education) at University of Split, Croatia. These students were chosen because they will probably meet children who may experience dental trauma in their future occupation. An online questionnaire was designed in the Google Form, and the link was sent to the representative student councils from each study, which forwarded it to other students. The population of the study included full-time students. Thus, 679 students of both genders from all academic years participated in this study. The inclusion criteria included undergraduate students, studying at University of Split during the academic year 2018/2019, and those who fully complet- snog odgoja i liječnici $(4-9)$. Slični rezultati dobiveni su i među studentima medicine, kineziologije i dentalne medicine $(3,8,19,11)$.

Ti rezultati uznemiruju jer su traume zuba hitna stanja koja se moraju zbrinuti odmah nakon što se dogode (10). Osim vremena koje je prošlo otkako se trauma dogodila pa do samog liječenja, prva pomoć na mjestu ozljede presudna je za kratkoročnu i dugoročnu prognozu ozlijeđenog zuba (12). Zato je potreban trenutačan i odgovarajući tretman osoba koje se nađu na mjestu nezgode. Neadekvatno znanje o pružanju odgovarajuće prve pomoći može učiniti nepopravljivu štetu (diskoloracija krune, mobilnost zuba, osjetljivost, nekroza pulpe, resorpcija korijena, fraktura zuba, gubitak zuba) $(3,13)$. U skladu s tim potrebno je da te profesije, ali i opća populacija, imaju odgovarajuće znanje o hitnim terapijskim postupcima u slučaju zubnih trauma. Uz to, vitalno je važno povećati svijest o protokolima hitnih slučajeva zubnih trauma kod mladih koji se školuju za te profesije. Potrebno je uključiti terapijske postupke dentalnih trauma u njihovo fakultetsko obrazovanje i pripremiti ih za djelovanje kada se pojave takve nepredvidive situacije (3).

Cilj ovog istraživanja bio je ispitati i usporediti razinu znanja studenata (medicinske i nemedicinske struke) Sveučilišta u Splitu o hitnom zbrinjavanju dentalnih trauma. Liječnici, nastavnici predškolskog odgoja, učitelji i nastavnici tjelesnog odgoja, zbog prirode svojega posla, mogu biti prvi koji će liječiti dentalnu ozljedu i njihova reakcija može odrediti uspjeh i prognozu daljnjeg postupka doktora dentalne medicine. Procjena razine znanja studenata iznimno je važna kako bi se upozorilo na potrebu dodatnih metoda edukacije - tečajeva o hitnim terapijskim postupcima trauma zuba kojima bi se poboljšalo njihovo znanje i samopouzdanje te uklonili problemi i nedoumice u takvim situacijama koje znaju biti izazovne i neugodne, čak i za profesionalce s više znanja $(13-18)$.

\section{Materijal i metode}

Ova presječna studija provedena je tijekom svibnja i lipnja 2019. godine. Upitnik na temelju kojega se procjenjivalo znanje o dentalnim traumama ispunili su studenti pet različitih studija - dva zdravstvenoga smjera (Medicina i Dentalna medicina) te tri nezdravstvenoga usmjerenja (Učiteljski studij, Studij za rani i predškolski odgoj i obrazovanje te Kineziološki fakultet) Sveučilišta u Splitu, Hrvatska. Izabrani su studenti s tih fakulteta jer će se oni u svojem budućem radu najvjerojatnije susresti s djecom koja su doživjela ozljedu zuba. Internetski upitnik osmišljen je u obliku Google Formsa, a njegova je poveznica poslana predstavnicima studenata svakog studija koji su ga zatim proslijedili ostalim kolegama. U studiju su bili uključeni redoviti studenti obaju spolova sa svih godina, te je njih 679 ispunilo upitnik. Kriteriji za sudjelovanje bili su: redoviti student na Sveučilištu u Splitu tijekom akademske godine 2018./2019. te potpuno ispunjen upitnik. U studiju nisu bili uključeni maloljetni stu- 
ed the questionnaire. The exclusion criteria were participants aged $<18$ years and those who had provided incomplete responses in the questionnaire. The objectives were explained to all the participants at the beginning of the questionnaire. The participation in the survey was voluntary. The study was anonymous and approved by the Ethics Committee of the School of Medicine (No: 2181-198-03-04-19-0055).

The questionnaire was based on different studies relating to the same topic, and it was divided into three sections, with a total of 24 questions $(11,14,15)$. The first section assessed demographic data (age, gender, study program), while the second part included ten questions regarding dental trauma training, experience and attitudes about dental trauma. The third part consisted of 10 closed-ended questions concerning the knowledge of dental traumatic injuries management, including questions covering the following areas: tooth identification, dental fragments reattachment, avulsed tooth replantation, cleaning, storage media and time elapsed between the event and the first aid provided. Each correct answer in the third part was scored one, and incorrect was scored 0 ; the maximum possible score was 10 . The total knowledge score for each respondent was calculated by adding up the number of correct answers, which was considered the primary outcome of the study. The respondents had to answer each question before submitting the form.

Experts in the dental field (a pediatric dentist, endodontist, and an oral surgeon) approved the content of the prepared questionnaire. As a test of reliability, the questionnaire was pilot-tested on 50 students whose questionnaires were excluded from the primary study sample. Internal consistency for total scores showed a Cronbach's coefficient alpha of 0.710 . The minimum required sample size $(\mathrm{n}=310)$ was calculated from the full number of students who attended the abovementioned five faculties in the academic years 20182019 ( $\mathrm{N}=1595)$ with a 95\% confidence interval, 5\% margin of error and a population proportion of $50 \%$.

Data were analyzed by the Statistical Package for the Social Science version 25 (SPSS, IBM Corp, Armonk, New York, USA). The Kolmogorov-Smirnov test evaluated the compliance with normal distribution of the dependent variable. A descriptive analysis was done by calculating the frequency and percentages of categorical data; qualitative data were expressed as a mean \pm standard deviation. A statistical analysis was conducted using Student t-test or one - way ANOVA, with Tukey's post-hoc test. The differences between categorical variables were tested using the $\chi 2$ test and Fisher's exact test. The influence of the independent variables (age, gender, dental trauma training, witnessed or experienced dental injuries) onto the dependent variable (knowledge score) was assessed using a general regression model (GRM). The results were expressed in the form of Pareto charts. The level of significance was set at $\mathrm{p}<0.05$.

\section{Results}

The study included 679 students, $82.5 \%$ female, and $17.5 \%$ male; mean age $22.14 \pm 1.93$, range $19-27$. The response rates were $84.4 \%$ for dental students (152/180), $25.0 \%$ for medical students (135/540), 65.0\% for preschool education students (130/200), 56.8\% for teacher's education stu- denti te oni koji nisu dali cjelovite odgovore na postavljena pitanja. Ciljevi istraživanja objašnjeni su svim sudionicima na početku ispunjavanja upitnika. Sudjelovanje je bilo potpuno dobrovoljno. Upitnik je bio anoniman i odobrilo ga je Etičko povjerenstvo Medicinskog fakulteta (br: 2181-19803-04-19-0055).

Upitnik koji se temeljio na nekoliko istraživanja povezanih istom temom, sastojao se od triju dijelova i sadržavao je ukupno 24 pitanja $(11,14,15)$. Prvi dio obuhvaćao je osnovne demografske i profesionalne podatke (spol, dob, studij, godina studiranja), a drugi se sastojao od deset pitanja vezanih za traumatske ozljede i terapijske postupke, iskustva i stajališta ispitanika. Treći dio sadržavao je 10 zatvorenih pitanja koja se odnose na znanja o terapijskim postupcima, uključujući i ona koja obuhvaćaju sljedeća područja: identifikaciju zuba, ponovno spajanje zubnih fragmenata, replantaciju izbijenog zuba, čišćenje, medije za transport izbijenog zuba i vrijeme proteklo između traume i trenutka pružanja prve pomoći. Svaki točan odgovor u trećem dijelu bodovan je jednim bodom, a za netočan dobivala se nula bodova; maksimalna moguća ocjena bila je 10. Ukupna ocjena znanja za svakog ispitanika izračunata je zbrajanjem točnih odgovora, što se smatralo glavnim rezultatom studije. Ispitanici su morali odgovoriti na sva pitanja prije slanja upitnika.

Stručnjaci iz raznih područja dentalne medicine (pedodont, endodont te oralni kirurg) odobrili su sadržaj pripremljenog upitnika. Kao test pouzdanosti upitnik je pokusno testiran na 50 studenata čiji su upitnici bili isključeni iz glavnog uzorka ove studije. Unutarnja dosljednost za ukupne rezultate pokazala je Cronbachov koeficijent alfa 0,710. Minimalna potrebna veličina uzorka $(\mathrm{n}=310)$ izračunata je iz ukupnog broja studenata koji su pohađali tih pet studija u akademskoj godini 2018./2019. ( $\mathrm{N}=1595) \mathrm{s}$ intervalom pouzdanosti od $95 \%$, s 5-postotnom granicom pogreške i distribucijom odgovora od $50 \%$.

Podatci su analizirani statističkim paketom za društvene znanosti, verzija 25 (SPSS, IBM Corp, Armonk, New York, SAD). Kolmogorov-Smirnovim testom procijenjena je normalnost distribucije odgovora. Deskriptivnom analizom izračunata je učestalost i postotak kategorijskih podataka, a kvalitativni podatci izraženi su kao srednja ocjena \pm standardna devijacija. Statistička analiza provedena je Studentovim t-testom ili jednosmjernom analizom varijance (ANOVA), s Tukeyijevim post-hoc testom. Razlike između kategorijskih varijabli testirane su $\chi 2$ testom i Fisherovim testom. Utjecaj nezavisnih varijabli (dob, spol, edukacija o dentalnim traumama, jesu li ispitanici svjedočili dentalnoj traumi ili su je sami iskusili) na zavisne varijable (znanje) određen je višestrukom linearnom regresijom. Rezultati su izraženi u obliku Paretovih dijagrama. Razina značajnosti postavljena je na $\mathrm{p}<0,05$.

\section{Rezultati}

Ukupno 679 studenata sudjelovalo je u istraživanju $82,5 \%$ žena i $17,5 \%$ muškaraca, srednja dob bila je 22,14 \pm 1,93, a raspon od 19 do 27. Upitnik je ispunilo 84,4 \% studenata studija Dentalne medicine (152/180), 25,0 \% studenata studija Medicine (135/540), 65,0 \% studenata studija 
dents (128/225), and $29.7 \%$ for physical education students (134/450). Demographic and professional characteristics of the participants are presented in Table 1. The overall mean knowledge of dental trauma emergency management among surveyed students was $4.32 \pm 2.25$. Dental students have shown the best results, compared to medical, physical education, preschool education and teachers' education students $(6.75 \pm 2.17$ vs $4.32 \pm 1.67,3.69 \pm 1.67,3.38 \pm 1.76$, and $3.05 \pm 1.55$ respectively; $\mathrm{p} \leq 0.001)$. However, the mean knowledge scores of both dental and medical students show a statistically significant difference when compared to students of other faculties. Other factors associated with higher levels of knowledge were age, year of study, received dental injuries training, self-assessment knowledge, being a witness of dental trauma, being informed and interested in learning about dental trauma $(\mathrm{p} \leq 0.001)$.
Ranog i predškolskog odgoja i obrazovanja (130/200), 56,8 $\%$ studenata Učiteljskog studija (128/225) i 29,7 \% studenata Kineziološkog fakulteta (134/450). Demografska i profesionalna obilježja ispitanika nalaze se u tablici 1 .

Ukupno srednje znanje o hitnim terapijskim postupcima u slučaju traume zuba iznosilo je kod ispitanih studenata $4,32 \pm 2,25$. Studenti dentalne medicine pokazali su najbolje znanje, u usporedbi sa studentima medicine, kineziologije te predškolskog i učiteljskog studija $(6,75 \pm 2,17$ vs. 4,32 $\pm 1,67,3,69 \pm 1,67,3,38 \pm 1,76$, i $3,05 \pm 1,55$ slijedom; $\mathrm{p} \leq$ $0,001)$. Prosječne ocjene znanja studenata dentalne medicine i medicine pokazuju statistički značajnu razliku u odnosu prema studentima drugih studija. Ostali čimbenici povezani $s$ većim znanjem bili su dob, godina studija, obrazovanje kad je riječ o dentalnim ozljedama, samoprocjena znanja, svjedo-

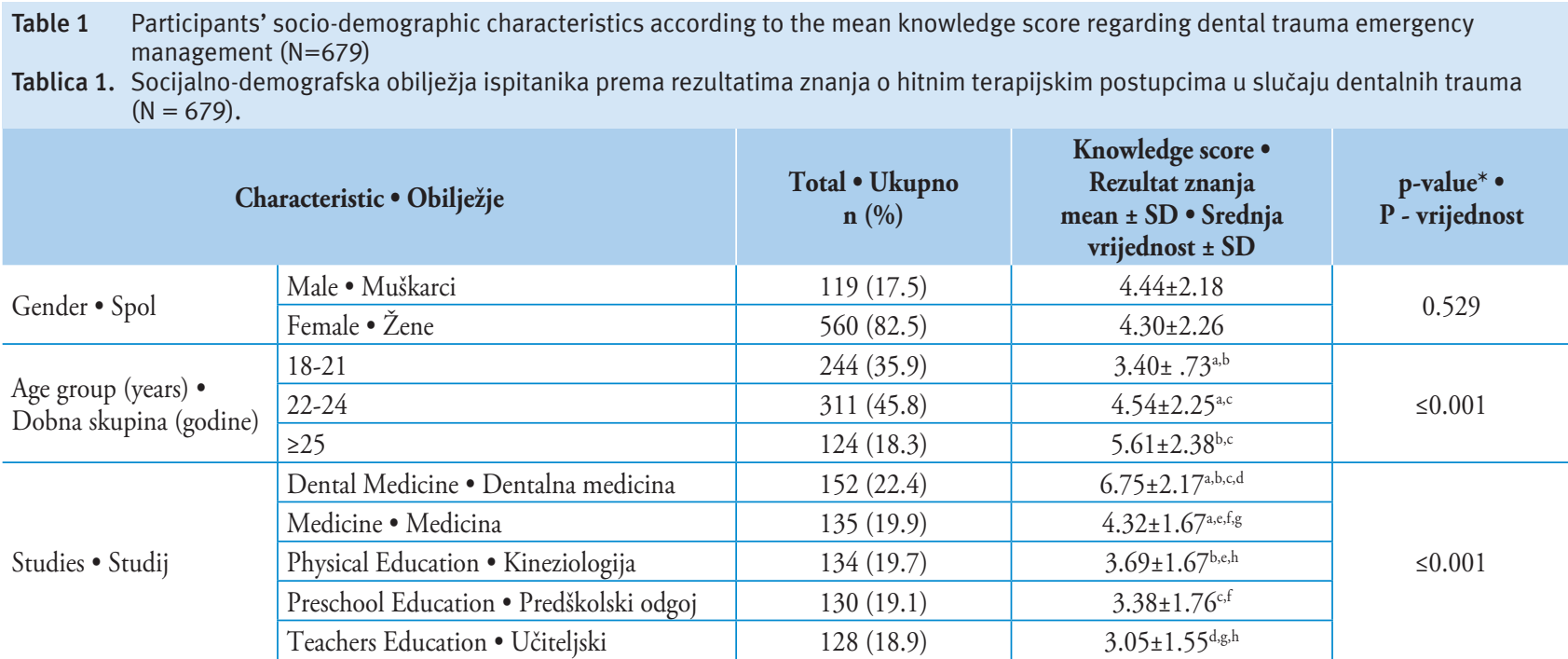

Data are presented as whole numbers and percentages or mean \pm SD. $\bullet$ Vrijednosti su prikazane kao cijeli broj i postotak ili srednja vrijednost i standardna devijacija.

${ }^{*}$ Statistical significance was tested by Student t-test or One-way ANOVA. Statistical significance was set to $\mathrm{p}<0.05$. The same superscript lower letter indicated a statistical difference between groups based on Tukey Test (ab,c,d,f,g,j,k,l,0,q,1,5 $\left.\mathrm{p} \leq 0.001,{ }^{e} \mathrm{p}=0.033,{ }^{\mathrm{h}, \mathrm{p}} \mathrm{p}=0.045,{ }^{\mathrm{i}} \mathrm{p}=0.003,{ }^{\mathrm{m}} \mathrm{p}=0.004,{ }^{\mathrm{n}} \mathrm{p}=0.002\right)$. Abbreviation: SD, standard deviation. • Statistička značajnost testirana je Studentovim t-testom ili jednosmjernom analizom varijance (ANOVA). Statistička značajnost postavljena je na $\mathrm{p}<0,05$. Isto nadpisano malo slovo upućuje na statističku razliku između grupa temeljem Tukey testa $\left(\left(\mathrm{a}, \mathrm{b}, \mathrm{c}, \mathrm{f}, \mathrm{f}, \mathrm{g}, \mathrm{k}, \mathrm{l}, \mathrm{o,o}, \mathrm{r}, \mathrm{s}, \mathrm{p} \leq 0,001,{ }^{\mathrm{e}} \mathrm{p}=0,033,{ }^{\mathrm{h}, \mathrm{p}} \mathrm{p}=0,045,{ }^{1} \mathrm{p}=0,003,{ }^{\mathrm{m}} \mathrm{p}=0,004,{ }^{\mathrm{n}} \mathrm{p}=0,002\right)\right.$. Skraćenica: SD - standardna devijacija

The evaluation of attitudes toward dental injuries according to the mean knowledge score of dental trauma emergency management is shown in Table 2. Only $12(1.8 \%)$ of surveyed students rated their knowledge as very good. At the same time, these students also showed the best knowledge compared to the ones who rated their knowledge as very poor, poor, fair and good $(8.25 \pm 1.28$ vs $3.54 \pm 1.77$, $3.75 \pm 1.82,4.43 \pm 2.13$, and $6.51 \pm 2.52 ; \mathrm{p} \leq 0.001)$. Approximately $50 \%(\mathrm{n}=376)$ of respondents considered important and very important the knowledge of dental trauma for their future professional work.

Only $20.9 \%$ of all tested students have received some form of dental trauma education during their studies. Those who underwent some education showed better knowledge $(6.78 \pm 2.23$ vs $3.67 \pm 1.65 ; \mathrm{p} \leq 0.001)$. Approximately $27.5 \%$ of students witnessed and $22.5 \%$ of them experienced traumatic tooth injuries. The students who suffered traumatic čenje traumi zuba, informiranost i zainteresiranost za edukaciju o ozljedama zuba $(\mathrm{p} \leq 0,001)$.

Procjena stajališta o ozljedama zuba prema prosječnom znanju o hitnim terapijskim postupcima traume zuba prikazana je u tablici 2. Samo $12(1,8 \%)$ ispitanih studenata ocijenilo je svoje znanje kao vrlo dobro. Istodobno su ti studenti pokazali i najbolje znanje u usporedbi s onima koji su svoje znanje ocijenili kao vrlo loše, loše, prosječno i dobro $(8,25 \pm$ 1,28 vs. $3,54 \pm 1,77,3,75 \pm 1,82,4,43 \pm 2,13$ i $6,51 \pm 2,52$; $\mathrm{p} \leq 0,001)$. Otprilike $50 \%(\mathrm{n}=376)$ ispitanika smatra znanje o dentalnim traumama važnim i vrlo važnim za svoj budući profesionalni rad.

Samo 20,9\% svih ispitanih studenata dobilo je neki oblik edukacije o traumama zuba tijekom studiranja. Oni koji su bili na nekoj vrsti izobrazbe pokazali su i bolje znanje $(6,78$ $\pm 2,23$ vs. $3,67 \pm 1,65$; $p \leq 0,001)$. Gotovo $27,5 \%$ ispitanika svjedočilo je traumatskoj ozljedi zuba, a njih $22,5 \%$ to je 
Table 2 Participants' attitudes toward dental trauma injuries according to the mean knowledge score regarding dental trauma emergency management $(\mathrm{N}=679)$

Tablica 2. Stajališta ispitanika o traumatskim ozljedama zuba prema rezultatima znanja o hitnim terapijskim postupcima u slučaju dentalnih trauma $(\mathrm{N}=679)$.

\begin{tabular}{|c|c|c|c|c|}
\hline \multicolumn{2}{|c|}{ Characteristic $\bullet$ Obilježje } & \multirow{2}{*}{$\begin{array}{c}\text { Total • Ukupno } \\
\text { n (\%) } \\
305(44.9) \\
\end{array}$} & \multirow{2}{*}{$\begin{array}{c}\begin{array}{c}\text { Knowledge score } \\
\text { Rezultat znanja } \\
\text { mean } \pm \text { SD } \bullet \text { Srednja } \\
\text { vrijednost } \pm \text { SD }\end{array} \\
3.43 \pm 1.80^{\mathrm{a}, \mathrm{b}}\end{array}$} & \multirow{2}{*}{$\begin{array}{l}\text { p-value* } \\
\text { P-vrijednost }\end{array}$} \\
\hline \multirow{3}{*}{$\begin{array}{l}\text { Informed about dental injuries } \bullet \text { Informirani o } \\
\text { traumatskim ozljedama zuba }\end{array}$} & Not informed $\bullet$ Neinformirani & & & \\
\hline & Partially informed • Djelomično informirani & $315(46.4)$ & $4.48 \pm 1.98^{\mathrm{a}, \mathrm{c}}$ & \multirow{2}{*}{$\leq 0.001$} \\
\hline & Completely informed $\bullet$ Potpuno informirani & $59(8.7)$ & $8.08 \pm 1.47^{\mathrm{b}, \mathrm{c}}$ & \\
\hline \multirow{5}{*}{$\begin{array}{l}\text { Self-assessed knowledge about dental injuries } \\
\text { Procjena znanja o traumatskim ozljedama zuba }\end{array}$} & Very poor $\bullet$ Veoma loše & $124(18.3)$ & $3.54 \pm 1.77^{\mathrm{d}, \mathrm{fgg}}$ & \multirow{5}{*}{$\leq 0.001$} \\
\hline & Poor • Loše & $255(37.6)$ & $3.75 \pm 1.82^{\mathrm{h}, \mathrm{Ij}}$ & \\
\hline & Fair • Prosječno & $207(30.5)$ & $4.43 \pm 2.13^{\mathrm{d}, \mathrm{h}, \mathrm{k}, \mathrm{l}}$ & \\
\hline & Good $\bullet$ Dobro & $81(11.9)$ & $6.51 \pm 2.52^{\mathrm{f}, \mathrm{I}, \mathrm{k}, \mathrm{m}}$ & \\
\hline & Very good $\bullet$ Veoma dobro & $12(1.8)$ & $8.25 \pm 1.28^{\mathrm{g}, \mathrm{j}, \mathrm{lm}}$ & \\
\hline \multirow{5}{*}{$\begin{array}{l}\text { Importance of knowledge of the management } \\
\text { of traumatic dental injuries for future work } \\
\text { Važnost znanja o hitnim terapijskim } \\
\text { postupcima ozljeda zuba u svrhu budućega } \\
\text { rada }\end{array}$} & Not important $\bullet$ Potpuno nevažno & $10(1.5)$ & $4.20 \pm 1.31^{\mathrm{n}}$ & \multirow{5}{*}{$\leq 0.001$} \\
\hline & Slightly important $\bullet$ Nevažno & $21(3.1)$ & $4.09 \pm 1.60^{\circ}$ & \\
\hline & Fairly important $\bullet$ Umjereno važno & $272(40.1)$ & $3.56 \pm 1.86^{\mathrm{p}}$ & \\
\hline & Important $\bullet$ Vrlo važno & $216(31.8)$ & $4.02 \pm 2.00^{9}$ & \\
\hline & Very important $\bullet$ Iznimno važno & $160(23.6)$ & $6.06 \pm 2.37^{\mathrm{n}, \mathrm{o}, \mathrm{p}, \mathrm{q}}$ & \\
\hline \multirow{2}{*}{$\begin{array}{l}\text { Received dental injuries training during } \\
\text { academic education } \bullet \text { Tijekom obrazovanja } \\
\text { slušali predavanja/seminare o traumatskim } \\
\text { ozljedama zuba }\end{array}$} & $\mathrm{No} \cdot \mathrm{Ne}$ & $537(79.1)$ & $3.67 \pm 1.65$ & \multirow[b]{2}{*}{$\leq 0.001$} \\
\hline & Yes $\bullet \mathrm{Da}$ & $142(20.9)$ & $6.78 \pm 2.23$ & \\
\hline \multirow{2}{*}{$\begin{array}{l}\text { Interested in future education about dental } \\
\text { injuries } \bullet \text { Zainteresirani za edukaciju o } \\
\text { traumatskim ozljedama zuba u budućnosti }\end{array}$} & $\mathrm{No} \cdot \mathrm{Ne}$ & $251(37.0)$ & $3.74 \pm 1.93$ & \multirow[b]{2}{*}{$\leq 0.001$} \\
\hline & Yes $\bullet$ Da & $428(67.0)$ & $4.67 \pm 2.35$ & \\
\hline \multirow{2}{*}{$\begin{array}{l}\text { Self-assessed knowledge about dental injuries } \\
\text { first aid - avulsion } \bullet \text { Procjena znanja o } \\
\text { terapijskom postupku - avulzija zuba }\end{array}$} & $\mathrm{No} \cdot \mathrm{Ne}$ & $406(59.8)$ & $3.61 \pm 1.74$ & \multirow{2}{*}{$\leq 0.001$} \\
\hline & Yes $• \mathrm{Da}$ & $273(40.2)$ & $5.39 \pm 2.48$ & \\
\hline \multirow{2}{*}{$\begin{array}{l}\text { Self assessed knowledge about dental injuries } \\
\text { first aid - tooth luxation } \bullet \text { Procjena znanja o } \\
\text { terapijskom postupku - luksacija zuba }\end{array}$} & $\mathrm{No} \cdot \mathrm{Ne}$ & $526(77.5)$ & $3.70 \pm 1.82$ & \multirow{2}{*}{$\leq 0.001$} \\
\hline & $\mathrm{Yes} \bullet \mathrm{Da}$ & $153(22.5)$ & $6.47 \pm 2.25$ & \\
\hline \multirow{2}{*}{$\begin{array}{l}\text { Self- assessed knowledge about dental injuries } \\
\text { first aid - tooth fracture } \bullet \text { Procjena znanja o } \\
\text { terapijskom postupku - fraktura zuba }\end{array}$} & $\mathrm{No} \bullet \mathrm{Ne}$ & $430(63.3)$ & $3.76 \pm 1.90$ & \multirow[b]{2}{*}{$\leq 0.001$} \\
\hline & Yes • Da & $249(36.7)$ & $5.30 \pm 2.47$ & \\
\hline \multirow{2}{*}{$\begin{array}{l}\text { Witnessed dental injures } \bullet \text { Svjedočili dentalnoj } \\
\text { traumi }\end{array}$} & $\mathrm{No} \cdot \mathrm{Ne}$ & $492(72.5)$ & $4.21 \pm 2.20$ & \multirow{2}{*}{0.034} \\
\hline & Yes $\bullet \mathrm{Da}$ & $187(27.5)$ & $4.63 \pm 2.34$ & \\
\hline \multirow{2}{*}{$\begin{array}{l}\text { Experienced dental injuries } \bullet \text { Doživjeli } \\
\text { dentalnu traumu }\end{array}$} & $\mathrm{No} \cdot \mathrm{Ne}$ & $528(77.8)$ & $4.25 \pm 2.26$ & \multirow{2}{*}{0.110} \\
\hline & Yes $\bullet \mathrm{Da}$ & $151(22.2)$ & $4.58 \pm 2.17$ & \\
\hline \multicolumn{5}{|c|}{ 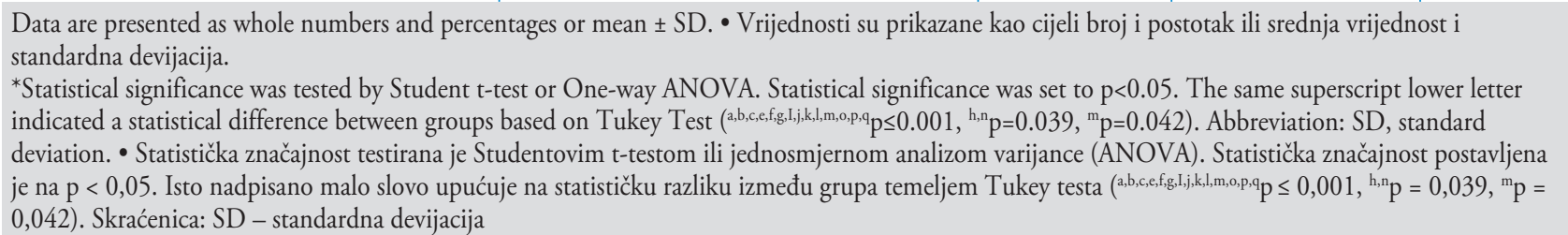 } \\
\hline
\end{tabular}

tooth injury showed better knowledge than those who did not, but it was statistically insignificant $(\mathrm{p}=0.110)$. The students who have witnessed traumatic tooth injury showed statistically significant better knowledge compared to those who have not $(4.63 \pm 2.34$ vs $4.21 \pm 2.20 ; \mathrm{p}=0.034)$.

The distribution of correct responses to questions regarding dental trauma management among students of different study programs is shown in Table 3. Dental students provided the highest percentage of correct answers.

Demographic data and respondents' attitudes toward dental injuries according to different study programs are shown in Table 4. There are differences in the responses between stu- i doživjelo. Studenti koji su pretrpjeli traumatsku ozljedu zuba pokazali su bolje znanje od onih koji nisu, ali statistički nevažno $(p=0,110)$. Studenti koji su bili svjedoci traumatskih ozljeda zuba pokazali su statistički značajno bolje znanje $\mathrm{u}$ usporedbi s onima koji to nisu $(4,63 \pm 2,34 \mathrm{u}$ odnosu prema 4,21 $\pm 2,20 ; p=0,034$ ).

Raspodjela točnih odgovora na pitanja vezana za terapijske postupke traumatskih ozljeda zuba među studentima različitih studijskih programa prikazana je u tablici 3. Studenti dentalne medicine dali su najveći postotak točnih odgovora.

Demografska obilježja i stajališta o traumatskim ozljedama zuba među studentima različitih studijia prikazani su u 
Table 3 Frequency of participants' answers to the questions regarding dental trauma emergency management according to attend study programs $(\mathrm{N}=679)$

Tablica 3. Raspodjela odgovora na pitanja o traumatskim ozljedama i hitnim terapijskim postupcima među studentima različitih studija $(\mathrm{N}=$ 679)

\begin{tabular}{|c|c|c|c|c|c|c|}
\hline \multicolumn{2}{|c|}{ Question • Pitanje } & $\begin{array}{l}\text { Dental medicine } \\
\text { Dentalna medicina } \\
\quad(\mathrm{n}=152)\end{array}$ & $\begin{array}{l}\text { Medicine } \\
\text { Medicina } \\
(\mathbf{n}=135)\end{array}$ & $\begin{array}{l}\text { Physical Education • } \\
\text { Kineziologija } \\
(\mathbf{n}=134)\end{array}$ & $\begin{array}{l}\text { Preschool Education • } \\
\text { Rani i predškolski odgoj } \\
(\mathbf{n = 1 3 0 )}\end{array}$ & $\begin{array}{l}\text { Teachers Education • } \\
\text { Učiteljski } \\
(\mathrm{n}=128)\end{array}$ \\
\hline \multirow{2}{*}{$\begin{array}{l}\text { Identify primary tooth } \\
\text { Identifikacija mliječnog zuba }\end{array}$} & $\begin{array}{l}\text { Incorrect } ・ \text { Netočno } \\
(\mathrm{n}, \%)\end{array}$ & $5(3.3)$ & $12(8.8)$ & $16(11.9)$ & $12(9.2)$ & $10(7.8)$ \\
\hline & $\begin{array}{l}\text { Correct • Točno } \\
(\mathrm{n}, \%)\end{array}$ & $147(96.7)$ & $123(91.1)$ & $118(88.1)$ & $118(90.8)$ & $118(92.2)$ \\
\hline \multirow{2}{*}{$\begin{array}{l}\text { Identify permanent tooth • } \\
\text { Identifikacija trajnog zuba }\end{array}$} & $\begin{array}{l}\text { Incorrect } \begin{array}{l}\text { Inetočno } \\
(\mathrm{n}, \%)\end{array} \\
\end{array}$ & $12(7.9)$ & $29(21.5)$ & $60(44.8)$ & $53(40.8)$ & $81(63.3)$ \\
\hline & $\begin{array}{l}\text { Correct・Točno } \\
(\mathrm{n}, \%)\end{array}$ & $140(92.1)$ & $106(78.5)$ & $74(55.2)$ & $77(59.2)$ & $47(36.7)$ \\
\hline \multirow{2}{*}{$\begin{array}{l}\text { Tooth fracture procedure } \\
\text { Terapijski postupak frakture } \\
\text { zuba }\end{array}$} & $\begin{array}{l}\text { Incorrect } \begin{array}{l}\text { Inetočno } \\
(\mathrm{n}, \%)\end{array} \\
\end{array}$ & $31(20.4)$ & $72(53.3)$ & $91(67.9)$ & $95(73.1)$ & 98 (76.6) \\
\hline & $\begin{array}{l}\text { Correct } \bullet \text { Točno } \\
(\mathrm{n}, \%)\end{array}$ & $121(79.6)$ & $63(46.7)$ & $43(32.1)$ & $35(26.9)$ & $35(23.4)$ \\
\hline \multirow{2}{*}{$\begin{array}{l}\text { Displacement tooth procedure } \\
\text { Terapijski postupak luksacije } \\
\text { zuba }\end{array}$} & $\begin{array}{l}\text { Incorrect } \begin{array}{l}\text { Inetočno } \\
(\mathrm{n}, \%)\end{array} \\
\end{array}$ & $110(72.4)$ & $132(97.8)$ & $129(96.3)$ & $124(95.4)$ & $122(95.3)$ \\
\hline & $\begin{array}{l}\text { Correct・ Točno } \\
(\mathrm{n}, \%)\end{array}$ & $42(27.6)$ & $3(2.2)$ & $5(3.7)$ & $6(4.6)$ & $6(4.7)$ \\
\hline \multirow{2}{*}{$\begin{array}{l}\text { Primary teeth replantation • } \\
\text { Replantacija mliječnog zuba }\end{array}$} & $\begin{array}{l}\text { Incorrect } ・ \text { Netočno } \\
(\mathrm{n}, \%)\end{array}$ & $33(21.7)$ & $34(25.2)$ & $55(41.0)$ & $48(36.9)$ & $60(46.9)$ \\
\hline & $\begin{array}{l}\text { Correct・ Točno } \\
(\mathrm{n}, \%)\end{array}$ & $119(78.3)$ & $101(74.8)$ & $79(59.0)$ & $82(63.1)$ & $68(53.1)$ \\
\hline \multirow{2}{*}{$\begin{array}{l}\text { Permanent teeth replantation } \\
\text { Replantacija trajnog zuba }\end{array}$} & $\begin{array}{l}\text { Incorrect } \begin{array}{l}\text { Inetočno } \\
(\mathrm{n}, \%)\end{array} \\
\end{array}$ & $38(25.0)$ & $72(53.3)$ & $86(64.2)$ & $101(77.7)$ & $101(78.9)$ \\
\hline & $\begin{array}{l}\text { Correct • Točno } \\
(\mathrm{n}, \%)\end{array}$ & $114(75.0)$ & $63(46.7)$ & $48(35.8)$ & $29(22.3)$ & $27(21.1)$ \\
\hline \multirow{2}{*}{$\begin{array}{l}\text { Tooth handling • } \\
\text { Držanje izbijenog zuba }\end{array}$} & $\begin{array}{l}\text { Incorrect } \bullet \text { Netočno } \\
(\mathrm{n}, \%)\end{array}$ & $39(25.7)$ & $81(60.0)$ & $92(68.7)$ & $103(79.2)$ & $90(70.3)$ \\
\hline & $\begin{array}{l}\text { Correct ・ Točno } \\
(\mathrm{n}, \%)\end{array}$ & $113(74.3)$ & $54(40.0)$ & $42(31.3)$ & $27(20.8)$ & $38(29.7)$ \\
\hline \multirow{2}{*}{$\begin{array}{l}\text { Tooth cleaning } \\
\text { Čišćenje izbijenog zuba }\end{array}$} & $\begin{array}{l}\text { Incorrect } \bullet \text { Netočno } \\
(\mathrm{n}, \%)\end{array}$ & $71(46.7)$ & $111(82.2)$ & $117(87.3)$ & $103(79.2)$ & $99(77.3)$ \\
\hline & $\begin{array}{l}\text { Correct ・ Točno } \\
(\mathrm{n}, \%)\end{array}$ & $81(53.3)$ & $24(17.8)$ & $17(12.7)$ & $27(20.8)$ & $29(22.7)$ \\
\hline \multirow{2}{*}{$\begin{array}{l}\text { Storage medium } \\
\text { Medij za pohranu izbijenog zuba }\end{array}$} & $\begin{array}{l}\text { Incorrect } \bullet \text { Netočno } \\
(\mathrm{n}, \%)\end{array}$ & $114(75.0)$ & $123(91.1)$ & $116(86.6)$ & $119(91.5)$ & $126(98.4)$ \\
\hline & $\begin{array}{l}\text { Correct ・ Točno } \\
(\mathrm{n}, \%)\end{array}$ & $38(25.0)$ & $12(8.9)$ & $18(13.4)$ & $11(8.5)$ & $2(1.6)$ \\
\hline \multirow{2}{*}{$\begin{array}{l}\text { Extra-alveolar period } \bullet \\
\text { Ekstraalveolarno vrijeme }\end{array}$} & $\begin{array}{l}\text { Incorrect } \bullet \text { Netočno } \\
(\mathrm{n}, \%)\end{array}$ & $40(26.3)$ & $100(74.1)$ & $83(61.9)$ & $102(78.5)$ & $99(77.3)$ \\
\hline & $\begin{array}{l}\text { Correct • Točno } \\
(\mathrm{n}, \%)\end{array}$ & $112(73.7)$ & $35(25.9)$ & $51(38.1)$ & $28(21.5)$ & $29(22.7)$ \\
\hline
\end{tabular}

Data are presented as whole numbers and percentages. $\bullet$ Vrijednosti su prikazane kao cijeli broj i postotak.

dents of various studies $(p \leq 0.001)$ except for the question of whether or not they witnessed traumatic tooth injury.

The association of measured overall dental injuries management knowledge score with respondent demographical data and attitudes toward dental trauma injuries as possible predictors are presented in Figure 1. A positive association of knowledge score was observed depending on student age $(\beta=0.722, p \leq 0.001)$. A similar relation was observed according to whether or not the student sustained a training on dental injuries during their academic education $(\beta=2.365$, $\mathrm{p} \leq 0.001$ ), and depending on personal assessment of the importance of knowledge regarding dental trauma emergency management $(\beta=0.433, p \leq 0.001)$. tablici 4. Postoje razlike u odgovorima između studenata različitih studija ( $\mathrm{p} \leq 0,001)$, osim na pitanje jesu li ikada svjedočili traumatskoj ozljedi zuba.

Povezanost dobivenog ukupnog rezultata znanja o terapijskim postupcima trauma zuba $s$ demografskim podatcima i stajalištima ispitanika kao mogućim prediktorima prikazani su na slici 1. Uočena je pozitivna povezanost rezultata znanja ovisno o dobi ispitanika $(\beta=0,722, p \leq 0,001)$. Slična povezanost uočena je ovisno o tome je li student tijekom školovanja sudjelovao u nekom obliku edukacije o traumatskim ozljedama zuba $(\beta=2,365, \mathrm{p} \leq 0,001)$ te ovisno o osobnoj procjeni o važnosti znanja o hitnim terapijskim postupcima u slučaju ozljede zuba $(\beta=0,433, \mathrm{p} \leq 0,001)$. 
Table 4 Comparison of demographic data and participants' attitudes toward dental injuries according to attended study programs ( $\mathrm{N}=679$ )

Tablica 4. Usporedba demografskih podataka i stajališta ispitanika o traumatskim ozljedama zuba (edukacija, terapija) - podijeljeno prema studijima $(\mathrm{N}=679)$

\begin{tabular}{|c|c|c|c|c|c|c|c|}
\hline \multicolumn{2}{|c|}{ Characteristic $\bullet$ Obilježje } & $\begin{array}{l}\text { Dental medicine } \\
\text { Dentalna medicina } \\
\quad(\mathrm{n}=152)\end{array}$ & $\begin{array}{c}\text { Medicine } \\
\text { Medicina } \\
(\mathbf{n}=135)\end{array}$ & $\begin{array}{l}\text { Physical Education • } \\
\text { Kineziologija } \\
(\mathbf{n}=134)\end{array}$ & $\begin{array}{c}\text { Preschool Education • } \\
\text { Rani i predškolski } \\
\text { odgoj } \\
(\mathbf{n}=130)\end{array}$ & $\begin{array}{c}\text { Teachers Education • } \\
\text { Učiteljski } \\
(\mathbf{n}=128)\end{array}$ & 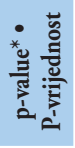 \\
\hline \multirow{2}{*}{ Gender $\bullet$ Spol } & Male $\bullet$ Muškarci & $25(16.4)$ & $31(22.9)$ & $60(44.8)$ & $1(0.8)$ & $2(1.6)$ & \multirow{2}{*}{$\begin{array}{l}\overrightarrow{8} \\
\dot{0} \\
\dot{v}\end{array}$} \\
\hline & Female $\bullet$ Žene & $127(83.6)$ & $104(77.1)$ & $74(55.2)$ & $129(99.2)$ & $126(98.4)$ & \\
\hline \multirow{3}{*}{$\begin{array}{l}\text { Age group (years) • Dobna } \\
\text { skupina (godine) }\end{array}$} & $18-21$ & $36(23.7)$ & $29(21.5)$ & $48(35.8)$ & $74(56.9)$ & $57(44.5)$ & \multirow{3}{*}{$\begin{array}{l}\overrightarrow{8} \\
\stackrel{+}{\circ} \\
\dot{0}\end{array}$} \\
\hline & $22-24$ & $75(49.3)$ & $56(41.5)$ & $78(58.2)$ & $45(34.6)$ & $57(44.5)$ & \\
\hline & $\geq 25$ & $41(27.0)$ & $50(37.0)$ & $8(6.0)$ & $11(8.5)$ & $14(10.9)$ & \\
\hline \multirow{3}{*}{$\begin{array}{l}\text { Informed about dental injuries } \\
\text { - Informirani o traumatskim } \\
\text { ozljedama zuba }\end{array}$} & $\begin{array}{l}\text { Not informed } \bullet \\
\text { Neinformirani } \\
\end{array}$ & $20(13.2)$ & $84(62.2)$ & $81(60.4)$ & $60(46.2)$ & $60(46.9)$ & \multirow{3}{*}{$\begin{array}{l}\overrightarrow{8} \\
\dot{\circ} \\
\dot{\mathrm{v}}\end{array}$} \\
\hline & $\begin{array}{l}\text { Partially informed } \\
\text { - Djelomično } \\
\text { informirani } \\
\end{array}$ & $77(50.7)$ & $51(37.8)$ & $53(39.6)$ & $67(51.5)$ & $67(52.3)$ & \\
\hline & $\begin{array}{l}\text { Completely } \\
\text { informed } \bullet \text { Potpuno } \\
\text { informirani } \\
\end{array}$ & $55(36.2)$ & $0(0.0)$ & $0(0.0)$ & $3(2.3)$ & $1(0.8)$ & \\
\hline \multirow{5}{*}{$\begin{array}{l}\text { Self-assessed knowledge about } \\
\text { dental injuries } \bullet \text { Samoprocjena } \\
\text { znanja o traumatskim } \\
\text { ozljedama zuba }\end{array}$} & Very poor $\bullet$ Vrlo loše & $17(11.2)$ & $43(31.9)$ & $28(20.9)$ & $23(17.7)$ & $13(10.2)$ & \multirow{5}{*}{$\begin{array}{l}\overrightarrow{8} \\
\dot{0} \\
\dot{v}\end{array}$} \\
\hline & Poor • Loše & $33(21.7)$ & $62(45.9)$ & $55(41)$ & $47(36.2)$ & $58(45.3)$ & \\
\hline & Fair • Prosječno & $44(28.9)$ & $25(18.5)$ & $43(32.1)$ & $49(37.7)$ & $46(35.9)$ & \\
\hline & Good・Dobro & $46(30.3)$ & $5(3.7)$ & $8(6.0)$ & $11(8.5)$ & $11(8.6)$ & \\
\hline & $\begin{array}{l}\text { Very good } \bullet \text { Vrlo } \\
\text { dobro }\end{array}$ & $12(7.9)$ & $0(0.0)$ & $0(0.0)$ & $0(0.0)$ & $0(0.0)$ & \\
\hline \multirow{5}{*}{$\begin{array}{l}\text { Importance of knowledge of } \\
\text { the management of traumatic } \\
\text { dental injuries for future work } \\
\text { Važnost znanja o hitnim } \\
\text { terapijskim postupcima } \\
\text { ozljeda zubi u svrhu budućeg } \\
\text { rada }\end{array}$} & $\begin{array}{l}\text { Not Important } \bullet \\
\text { Potpuno nevažno }\end{array}$ & $1(0.7)$ & $4(3.0)$ & $3(2.2)$ & $0(0.0)$ & $2(1.6)$ & \multirow{5}{*}{$\begin{array}{l}\overrightarrow{8} \\
\stackrel{8}{0} \\
\dot{0}\end{array}$} \\
\hline & $\begin{array}{l}\text { Slightly important • } \\
\text { Nevažno }\end{array}$ & $0(0.0)$ & $7(5.2)$ & $7(5.2)$ & $2(1.5)$ & $5(3.9)$ & \\
\hline & \begin{tabular}{|l} 
Fairly important $\bullet$ \\
Umjereno važno
\end{tabular} & 7 (4.6) & $86(63.7)$ & 64 (47.8) & $62(47.7)$ & $53(41.4)$ & \\
\hline & $\begin{array}{l}\text { Important・Vrlo } \\
\text { važno }\end{array}$ & $33(21.7)$ & $29(21.5)$ & $50(37.3)$ & $52(40)$ & $52(40.6)$ & \\
\hline & $\begin{array}{l}\text { Very important • } \\
\text { Iznimno važno }\end{array}$ & $111(73.0)$ & $9(6.7)$ & $10(7.5)$ & $14(10.8)$ & $16(12.5)$ & \\
\hline \multirow{2}{*}{$\begin{array}{l}\text { Received dental injuries } \\
\text { and first aid training during } \\
\text { academic education } \bullet \text { Tijekom } \\
\text { obrazovanja slušali predavanja/ } \\
\text { seminare o traumatskim } \\
\text { ozljedama zuba }\end{array}$} & $\mathrm{No} \cdot \mathrm{Ne}$ & $46(30.3)$ & $122(90.4)$ & $123(91.8)$ & $124(95.4)$ & $122(95.3)$ & \multirow{2}{*}{$\begin{array}{l}\overrightarrow{8} \\
\dot{0} \\
\dot{v}\end{array}$} \\
\hline & Yes $• \mathrm{Da}$ & $106(69.7)$ & $13(9.6)$ & $11(8.2)$ & $6(4.6)$ & $6(4.7)$ & \\
\hline \multirow{2}{*}{$\begin{array}{l}\text { Interested in future education } \\
\text { about dental injuries } \\
\text { Zainteresirani za edukaciju o } \\
\text { traumatskim ozljedama zuba u } \\
\text { budućnosti }\end{array}$} & $\mathrm{No} \bullet \mathrm{Ne}$ & $15(9.9)$ & $82(60.7)$ & $54(40.3)$ & $49(37.7)$ & $51(39.8)$ & \multirow{2}{*}{$\begin{array}{l}\overrightarrow{8} \\
\dot{\dot{\theta}} \\
\mathrm{v}_{1}\end{array}$} \\
\hline & Yes $\bullet \mathrm{Da}$ & $137(90.1)$ & $53(39.3)$ & $80(60.0)$ & $81(62.3)$ & 77 (60.2) & \\
\hline \multirow{2}{*}{$\begin{array}{l}\text { Witnessed dental injures } \\
\text { Svjedočili dentalnoj traumi }\end{array}$} & $\mathrm{No} \cdot \mathrm{Ne}$ & $105(69.1)$ & 94 (69.6) & $100(74.6)$ & $98(75.4)$ & $95(74.2)$ & \multirow{2}{*}{$\underset{0}{\infty}$} \\
\hline & Yes • Da & $47(30.9)$ & $41(30.4)$ & $34(25.4)$ & 32 (24.6) & $33(25.8)$ & \\
\hline \multirow{2}{*}{$\begin{array}{l}\text { Experienced dental injuries } \\
\text { Doživjeli dentalnu traumu }\end{array}$} & $\mathrm{No} \cdot \mathrm{Ne}$ & 118 (77.6) & $102(75.6)$ & $95(70.9)$ & $102(78.5)$ & $111(86.7)$ & \multirow{2}{*}{$\stackrel{\circ}{\stackrel{+}{0}}$} \\
\hline & Yes $• \mathrm{Da}$ & $34(22.4)$ & $33(24.4)$ & $39(29.1)$ & $28(21.5)$ & $17(13.3)$ & \\
\hline
\end{tabular}

Data are presented as whole numbers and percentages. $\bullet$ Vrijednosti su prikazane kao cijeli broj i postotak.

*Statistical significance was tested by Chi square or Fisher's exact test. Statistical significance was set to $p<0.05$. $\bullet$ Statistička značajnost bila je testirana Hi-kvadrat ili Fisherovim egzaktnim testom. Statistička značajnost je postavljena na $\mathrm{p}<0,05$.

\section{Discussion}

The objective of this cross-sectional study was to examine the level of knowledge and experience of dental trauma among the students from different fields of study, future educational and health professionals. We compared the knowl-

\section{Rasprava}

Cilj ovog presječnog istraživanja bio je procijeniti razinu znanja i iskustvo o traumatskim ozljedama zuba među studentima pet različitih studija, budućih stručnjaka iz područja obrazovanja i medicinskih područja. Usporedili smo znanje o 


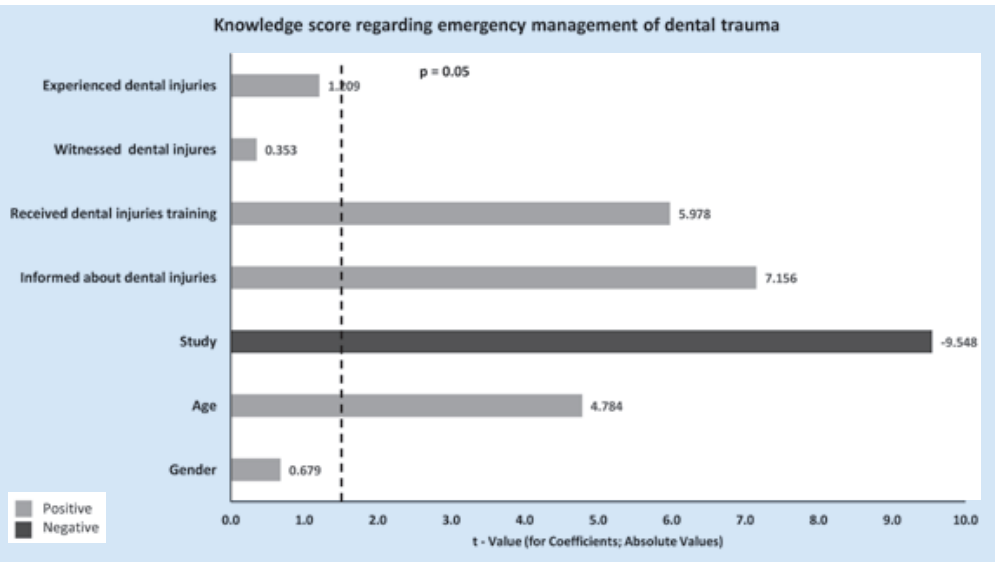

Figure 1 Multiple linear regression analysis. Significant dependence of measured overall dental injuries management knowledge score with participant demographic data and attitudes toward dental trauma injuries as possible predictors.

Slika 1. Višestruka linearna regresija analiza. Značajna ovisnost izmjerenog ukupnog rezultata znanja o liječenju traumatskih ozljeda zuba s demografskim podatcima i stajalištima ispitanika o traumatskim ozljedama zuba.

edge of dental trauma emergency management among dental, medical, preschool education, teacher' education, and physical education students. The total students' knowledge score regarding emergency management of dental trauma was $4.32 \pm 2.25$, with a maximum possible score of 10 . As expected, the best results were shown by dental students, compared to students of other studies $(\mathrm{p} \leq 0.001)$. Among the surveyed students, medical students showed second-best knowledge, however, the level of their knowledge is still insufficiently high. Although future physicians will deal with dental trauma in their work, the majority of tested medical students (63.7\%) believed that dental trauma knowledge is moderately important for their future professional practice. Besides, most of them are not interested in additional education on this subject (60.7\%). Inadequate knowledge of medical students and physicians was reported in numerous studies $(10,14,19-22)$. In the present study, insufficient knowledge was also shown by preschool education and teacher's education students. There are numerous studies confirming a low level of knowledge about dental trauma among preschool education teachers/students and teachers' education students / school teachers in Croatia and other countries (5-7,23).

The lack of knowledge amongst the tested groups may be due to inadequacy or complete lack of training for the management of traumatic dental injuries. Only 59 (8.7\%) of the total of 679 respondents stated that they were fully informed about traumatic tooth injuries, and only $12(1.8 \%)$ of them reported that their knowledge was very good. These results are supported by the fact that only $142(20.9 \%)$ respondents received dental trauma training during their university education. Most of dental students are well informed about dental injuries. In contrast, students from the other four studies are partially informed or not informed at all. Self-assessed knowledge about dental injuries among tested students is mostly inadequate (very poor, poor and fair). These results are in correspondence with previously published studies on health and educational professionals $(3,5,10,11,20,24)$. A small number of previously published studies compared the knowledge and the attitude before and after dental health education. Health education intervention (posters, lectures, hitnim terapijskim postupcima u slučaju trauma zuba među studentima dentalne medicine, medicine, predškolskog odgoja i obrazovanja, kineziologije i budućih učitelja. Ukupna ocjena znanja o hitnim postupcima nakon traumatske ozljede zuba iznosila je 4,32 $\pm 2,25$, s maksimalnom mogućom ocjenom 10. Očekivano su najbolje rezultate postigli studenti dentalne medicine, u usporedbi sa studentima drugih studija ( $p \leq 0,001)$. Među ispitanim studentima oni s medicine imali su drugi najbolji rezultat, ali još na nedovoljnoj razini. Iako će se budući liječnici sigurno susretati s traumatskim ozljedama zuba, većina ispitanih studenata medicine $(63,7 \%)$ smatrala je da je znanje o toj temi umjereno važno za njihov budući profesionalni rad. Istaknimo da većina nije bila zainteresirana za dodatnu izobrazbu o toj temi $(60,7 \%)$. Istaknimo da je u mnogobrojnim studijama zabilježeno nedovoljno znanje studenata medicine i liječnika $(10,14,19$ - 22).

$\mathrm{U}$ ovom istraživanju prikazano je i nedovoljno znanje studenata studija Ranog i predškolskog odgoja i obrazovanja te Učiteljskog studija. U mnogobrojnim istraživanjima autori su isticali nisku razinu znanja o traumama zuba među odgojiteljima/studentima predškolskog odgoja i obrazovanja te učiteljima/studentima učiteljskih fakulteta u Hrvatskoj i drugim zemljama $(5-7,23)$.

Nedostatno znanje ispitivanih skupina može biti posljedica neodgovarajućeg ili potpunog nedostatka edukacije o hitnim terapijskim protokolima u slučaju traumatskih ozljeda zuba. Samo 59 (8,7 \%) od ukupno 679 ispitanika izjavilo je da su cjelovito informirani o traumatskim ozljedama zuba, a samo $12(1,8 \%)$ istaknulo je da je njihovo znanje o toj temi vrlo dobro. Ti rezultati potkrijepljeni su činjenicom da su samo $142(20,9 \%)$ ispitanika pohađala neku vrstu edukacije o traumama zuba tijekom sveučilišnog obrazovanja. Većina studenata dentalne medicine dobro je informirana o zubnim traumama. Za razliku od njih studenti ostalih četiriju studija djelomično su informirani ili uopće nisu informirani. Samoprocijenjeno znanje o traumatskim ozljedama zuba kod ispitanih studenata uglavnom je neadekvatno (vrlo loše, loše i prosječno). Ti su rezultati u skladu $s$ već objavljenim istraživanjima provedenima među zdravstvenim i obrazovnim stručnjacima $(3,5,10,11,20,24)$. U nekoliko dosadaš- 
videos) can significantly improve the knowledge about the correct management of dental injuries (25-27).

Most of dental students, (94.7\%), considered the knowledge of emergency dental management significant for their professional life and were interested in further education on this subject (90.1\%). Similar results were reported in a study conducted in Saudi Arabia, where $95.7 \%$ of dental students considered education on dental injuries extremely important (11). A small number of medical students shared the same opinion. Only $28.2 \%$ of them considered the knowledge of emergency dental trauma treatment crucial for their future work, whereas $39.3 \%$ of them were interested in additional education. Conversely, a study conducted on medical students from the University of Rijeka (Croatia) showed that the majority of students were willing to gain further knowledge regarding this subject (10).

Furthermore, a previously published study conducted on a sample of pediatricians from Croatia showed that they are aware about the importance of timely treatment and a desire for continuous education on dental trauma management (17). Among the tested students of physical education, teachers' education and preschool education, approximately $60 \%$ of them showed interest in future education and nearly $50 \%$ of them have considered awareness of dental trauma management important for their future work. Bakarcic et al. (5) in their survey conducted on Croatian teachers, showed that $93 \%$ of students did not receive any formal training on this subject, yet over $87.0 \%$ of them were willing to participate in the training on such a subject. Similar results regarding the teacher population were obtained in other countries $(28,29)$.

Dental students showed the best knowledge about dental trauma emergency management, according to their responses. Approximately $90 \%$ of the students from all studies answered correctly the question regarding the identification of deciduous tooth. In contrast, the results regarding the question of identifying a permanent tooth were not so positive. Teachers' education students showed the lowest scores; only $36.7 \%$ of them correctly identified a permanent tooth, which points to inadequate general knowledge of study groups regarding the time of eruption of a permanent tooth. A differentiation between the two types of dentitions is important for the selection of proper therapeutic procedure in certain traumatic tooth injuries. Most of the students from all tested study programs knew that deciduous avulsed tooth should not be replanted. Nevertheless, only $46.7 \%$ of medical, $35.8 \%$ of physical education, $22.3 \%$ of preschool education, and $21.1 \%$ of teachers' education students knew that a permanent tooth can be replanted after avulsion. Previously published studies also reported poor knowledge on this subject for teachers $(30,31)$.

If replantation is not possible at the site of the accident, the tooth should be immediately placed in a suitable medium (milk, patient's mouth/saliva, and special storage media) that will allow PDL cells to survive until the moment of replantation (5). The present study did not find a satisfactory response rate regarding the storage medium. Only $25.0 \%$ of dental students provided all correct answers. Likewise, only $13.4 \%$ of physical education students, $8.9 \%$ of medical stu- njih istraživanja uspoređeni su znanje i stajališta prije edukacije o terapijskim postupcima u slučaju trauma zuba i nakon nje. Razne metode zdravstvene izobrazbe (posteri, predavanja, videozapisi) mogu znatno poboljšati znanje o hitnim terapijskim postupcima u slučaju trauma $(25-27)$.

Većina ispitanih studenata dentalne medicine $(94,7 \%)$ smatrala je znanje o hitnim terapijskim postupcima iznimno važnim za svoj profesionalni rad te su zainteresirani za daljnje obrazovanje kad je riječ o toj temi $(90,1 \%)$. Slični rezultati zabilježeni su u studiji provedenoj u Saudijskoj Arabiji gdje je $95,7 \%$ studenata dentalne medicine edukaciju o traumatskim ozljedama zuba smatralo iznimno važnom (11). Mali broj studenata medicine dijelilo je isto mišljenje. Samo njih $28,2 \%$ smatra da je znanje o hitnom liječenju trauma zuba presudno za njihov budući rad, a 39,3\% bilo je zainteresirano za dodatnu izobrazbu. Suprotno tomu, studija provedena na studentima medicine Sveučilišta u Rijeci (Hrvatska) pokazala je da je većina studenata voljna steći daljnje spoznaje o toj tematici (10).

Nadalje, studija provedena na uzorku pedijatara iz $\mathrm{Hr}$ vatske pokazala je njihovu svijest o važnosti pravodobnog liječenja i želju za kontinuiranom izobrazbom o traumama zuba (17). Među ispitanim studentima Kineziološkog fakulteta, Učiteljskog studija te studija Ranog i predškolskog odgoja i obrazovanja, otprilike njih $60 \%$ pokazalo je zanimanje za buduću izobrazbu, a otprilike $50 \%$ smatralo je znanje o traumama zuba važnim za njihov budući rad. Bakarčić i suradnici (5) u svojem su istraživanju provedenom na hrvatskim učiteljima pokazali da njih $93 \%$ nema nikakvu formalnu izobrazbu o toj temi, a ipak ih je više od 87,0 \% spremno sudjelovati u nekom obliku edukacije. Slični rezultati za učiteljsku populaciju dobiveni su i u drugim zemljama $(28,29)$.

Studenti dentalne medicine pokazali su najbolje znanje u svim pitanjima vezanima za hitne terapijske postupke traumatskih ozljeda zuba. Oko $90 \%$ studenata sa svih pet studija odgovorilo je točno na pitanje o identifikaciji mliječnog zuba. Suprotno tomu, odgovori na pitanje o identifikaciji trajnog zuba nisu bili tako uspješni. Studenti Učiteljskog studija imali su najlošije rezultate - samo njih 36,7 \% uspješno je identificiralo trajni zub. To upozorava da je neadekvatno opće znanje ispitanih skupina o vremenu erupcije trajnoga zuba. Razlika između dviju vrsta denticija važna je za odabir pravilnoga terapijskog postupka kod određenih traumatskih ozljeda zuba. Većina studenata svih ispitivanih studijskih programa zna da se izbijeni mliječni zub ne smije replantirati. Unatoč tomu, samo 46,7 \% studenata Medicinskog studija, 35,8 \% Kineziološkog fakulteta, 22,3 \% studija Ranog i predškolskog odgoja te 21,1 \% Učiteljskog studija znaju da se trajni zub nakon avulzije može replantirati. Prije objavljene studije u kojima su ispitanici bili učitelji također su pokazale loše poznavanje te teme $(30,31)$.

Ako replantacija nije moguća na mjestu ozljede, zub se treba odmah smjestiti u odgovarajući medij (mlijeko, usta / slina ozlijeđene osobe, posebni mediji za čuvanje zuba) koji će omogućiti stanicama parodontnog ligamenta da prežive do trenutka replantacije (5). $\mathrm{U}$ ovom istraživanju nije postignuta zadovoljavajuća stopa točnih odgovora u vezi s medijem za čuvanje izbijenog zuba. Sve točne odgovore ponudilo 
dents, $8.5 \%$ of preschool and $1.6 \%$ of teacher's education students answered correctly the questions regarding the storage medium. A study conducted on dental students in Saudi Arabia and Japan has obtained better results $(11,32)$. De Oliveira et al. (8) showed that $31.1 \%$ of physical education students would keep a tooth in a dry medium (handkerchief, a piece of cloth, in their hand), while $7.5 \%$ of them would keep it in milk and $7.5 \%$ of them in their mouth (saliva). Prasanna et al. (30) reported that $39.0 \%$ of 300 primary school teachers thought that the knocked-out tooth should be kept in a cotton roll, while only $3.0 \%$ of them stated milk as a suitable medium. Concerning the adequate extra-oral time for replantation, $73.7 \%$ of dental students answered correctly (immediate replantation). Other studies reported similar results $(11,32)$. Slightly smaller number of dental students in Saudi Arabia successfully answered the same question (67.5\%) (11). Only $38.1 \%$ of physical education students answered correctly, while in Spain, the same answer was provided by $25.0 \%$ of students (24).

As expected, older students ( $\geq 25$ years old) showed better knowledge than their younger colleagues $(\mathrm{p} \leq 0.001)$. This can be explained by the fact that dental and medical students encounter the examined topic in their higher years of study. In most studies, the age of participants had no effect or was positively significantly related to the knowledge level of dental trauma and its management $(9,11,14,29,31,32)$. In contrast, some studies have confirmed the fact that older dentists have more deficient knowledge than their younger colleagues $(33,34)$.

The students who have witnessed dental trauma showed to possess better knowledge since they presented a higher prevalence of correct answers $(\mathrm{p}=0.034)$. Interestingly, those that experienced dental trauma personally did not show better results. Approximately $30.0 \%$ of dental and medical students have witnessed dental trauma. The majority of those who suffered tooth injury themselves were from Physical Education $(29.1 \%)$, and the smallest number of them were from the Teachers Education Study (13.3\%). Out of 199 physical education students examined by de Oliveira et al. (8), only $34.7 \%$ of them had dental injury personally. Nikolic et al. (16) reported that $29.0 \%$ of pediatricians experienced dental trauma, while $69.0 \%$ of them witnessed trauma in their medical practice more than once.

\section{Conclusion}

From the results obtained in the current study, it could be concluded that students' knowledge about the emergency management of dental trauma is insufficient. Although this study was conducted at only one university in Croatia, these results emphasize the importance of additional student education aiming to improve the outcomes of dental trauma treatment. The majority of students who participated in the current study considered the training on emergency management relevant to their particular profession. Since most of the studied groups have shown an interest in training on this topic, it would be benificial if such a training becomes an integral part of their study curricula. je samo $25,0 \%$ studenata dentalne medicine, $13,4 \%$ studenata kineziologije, 8,9 \% studenata medicine, 8,5 \% ranog i predškolskog odgoja i obrazovanja te samo $1,6 \%$ studenata Učiteljskog studija. U istraživanjima provedenima među studentima dentalne medicine u Saudijskoj Arabiji i Japanu dobiveni su bolji rezultati $(11,32)$. De Oliveira i suradnici (8) pokazali su da bi $31,1 \%$ studenata kineziologije čuvalo izbijeni zub u suhom mediju (rupčić, komad tkanine, u ruci), $7,5 \%$ čuvalo bi zub u mlijeku, a 7,5 \% u ustima (slini). Prasanna i suradnici (30) izvijestili su da je 39,0 \% od 300 učitelja u osnovnoj školi smatralo da izbijeni zub treba čuvati u pamučnoj vatici, a samo je 3,0 \% navelo mlijeko kao prikladan medij. Kad je riječ o odgovarajućem ekstraoralnom vremenu za replantaciju, 73,7 \% studenata dentalne medicine odgovorilo je točno (trenutačna replantacija). U ostalim studijama dobiveni su slični rezultati $(11,32)$. Nešto manje studenata dentalne medicine u Saudijskoj Arabiji odgovorilo je točno na isto pitanje $(67,5 \%)(11)$. Samo $38,1 \%$ studenata kineziologije odgovorilo je točno na isto pitanje, a u Španjolskoj $25,0 \%$ (24).

Očekivano, stariji studenti ( $\geq 25$ godina ) pokazali su bolje znanje od mlađih kolega $(\mathrm{p} \leq 0,001)$. To se može objasniti činjenicom da se studenti dentalne medicine i medicine susreću s navedenom temom na višim godinama studija. $\mathrm{U}$ većini objavljenih istraživanja dob ispitanika nema nikakav utjecaj ili je pozitivno povezana sa znanjem ispitanika o dentalnim traumama i njihovu liječenju $(9,11,14,29,31,32)$. Za razliku od toga, u nekim istraživanjima autori potvrđuju da stariji doktori dentalne medicine imaju nedostatnije znanje od svojih mladih kolega $(33,34)$.

Studenti koji su bili svjedoci traume zuba imali su bolje znanje jer su pokazali veću prevalenciju točnih odgovora $(\mathrm{p}=$ $0,034)$. Zanimljivo, oni koji su osobno doživjeli traumatsku ozljedu zuba nisu pokazali bolje rezultate. Otprilike 30,0 \% studenata dentalne medicine i medicine svjedočilo je traumi zuba. Većina onih koji su sami pretrpjeli ozljedu bili su studenti kineziologije (29,1\%), a najmanje ih je bilo s Učiteljskog studija (13,3\%). Od 199 studenata kineziologije koje su ispitali de Oliveira i suradnici (8), njih 34,7 \% doživjelo je traumatsku ozljedu zuba. Nikolić i suradnici (16) izvijestili su da je 29,0 \% pedijatara doživjelo traumu zuba, a 69,0 \% svjedočilo je traumi u svojoj medicinskoj praksi više od jedanput.

\section{Zaključak}

Iz rezultata se može zaključiti da znanje studenta o liječenju traumatskih ozljeda zuba ne zadovoljava. Iako je ovo istraživanje provedeno na samo jednom sveučilištu u Hrvatskoj, dobiveni rezultati pokazuju koliko je važna dodatna edukacija studenata sa svrhom da se poboljšaju rezultati liječenja trauma zuba. Budući da je većina ispitivanih skupina pokazala zanimanje za izobrazbu o toj temi, bilo bi poželjno da ona postane sastavni dio njihovih studijskih programa jer je u nekoj mjeri bitna za određenu struku. 


\section{Acknowledgements}

We did not have any sources of funding directly relevant to the content of this manuscript. The authors received no financial support for the research. The authors wish to thank all participants for their invaluable contribution to this study.

\section{Conflict of interest}

The authors declare no conflict of interest.

\section{Contributors}

I.I. and L.G. - contributed to acquisition, analysis and interpretation of the data; drafting and providing final approval of the version to be published; D.J., N.G, N.Z.V. and D.M. -contributed to interpretation of the data; drafting the article and providing final approval of the version to be published; A.T. - contributed to the design and concept; acquisition, analysis and interpretation of the data; drafting and critical revision, supervision of the study and providing final approval of the version to be published.

\section{Zahvale}

Nismo imali izvore financiranja koji bi bili izravno vezani za sadržaj ovog rukopisa. Autori nisu dobili financijsku potporu za istraživanje. Autori žele zahvaliti svim sudionicima na neprocjenjivom doprinosu ovoj studiji.

\section{Sukob interesa}

Autori nisu bili u sukobu interesa.

\section{Doprinos autora}

I. I. i L. G. - pridonijele su prikupljanju, analizi i interpretaciji podataka te pisanju i potvrdi konačne verzije ovog rada; D. J., N. G., N. Z. V. i D. M. - doprinijeli su tumačenju podataka, pisanju i potvrdi konačne verzije ovog rada; A. T. - pridonijela je dizajnu i konceptu, prikupljanju, analizi i interpretaciji podataka, izradi i kritičkoj reviziji, nadzoru studije te potvrdi konačne verzije ovog rada

\section{Sažetak}

Svrha rada: Traume zuba kod djece čest su problem i svatko tko s njima radi trebao bi imati dovoljno znanja i vještina da u slučaju traume može osigurati odgovarajuću pomoć na mjestu nezgode. Cilj rada bio je procijeniti znanje studenata o hitnim terapijskim postupcima u slučaju dentalnih trauma kako bi u svojoj budućoj karijeri znali zbrinuti takve ozljede. Materijal i metode: Presječno istraživanje o hitnim terapijskim postupcima u slučaju dentalnih trauma provedeno je na temelju upitnika koji je ispunilo 679 studenata s pet različitih studija. Dobiveni podatci analizirani su Studentovim t-testom ili jednosmjernom analizom varijance (ANOVA), Tukeyijevim post-hoc testom te višestrukom linearnom regresijskom analizom $(p<0,05)$. Rezultati: Ukupna srednja vrijednost znanja studenata o hitnom liječenju dentalnih trauma bila je 4,32 $\pm 2,25$ (maksimalno 10). Uočena je pozitivna povezanost znanja s dobi studenta $(\beta=0,722, P \leq 0,001)$, ovisno o tome jesu li tijekom akademskog obrazovanja dobili neki oblik edukacije o zbrinjavanju dentalnih trauma $(\beta=2,365, P \leq 0,001)$ te o njihovoj osobnoj procjeni o važnosti znanja kad je riječ o hitnim terapijskim postupcima $(\beta=0,433, P \leq 0,001)$. Zaključak: Može se zaključiti da ispitani studenti posjeduju ograničeno znanje o traumama zuba te o postupcima njihova zbrinjavanja. Dobiveni rezultati pokazuju koliko je važna dodatna izobrazba svih koji bi se mogli susretati s traumama zuba tijekom svojega rada kako bi se postigli što bolji rezultati u liječenju dentalnih trauma.
Zaprimljen: 30. travnja 2020.

Prihvaćen: 1. rujna 2020.

Adresa za dopisivanje

Antonija Tadin,

Sveučilište u Splitu

Studij dentalne medicine

Zavod za restaurativnu dentalnu

medicinu i endodonciju,

Šoltanska 2, 21000 Split, Hrvatska

ORCID ID: 0000-0002-5365-9816;

telefon: +38598609191 ,

faks: +38521557624

e-adresa: atadin@mefst.hr

Ključne riječi

ozljede zuba; hitni postupci; studenti; zdravstvene spoznaje stavovi i praksa

\section{References}

1. Lam R. Epidemiology and outcomes of traumatic dental injuries: a review of the literature. Aust Dent J. 2016 Mar;61 Suppl 1:4-20.

2. Diangelis AJ, Andreasen JO, Ebeleseder KA, Kenny DJ, Trope M, Sigurdsson A, et al. International Association of Dental Traumatology guidelines for the management of traumatic dental injuries: 1 . Fractures and luxations of permanent teeth. Dent Traumatol. 2012 Feb;28(1):2-12.

3. Nagata JY, Gois VLA, Munchow EA, Albuquerque MTP. Dental trauma education intervention as a positive influence among undergraduate students. Eur J Dent. 2018 Oct-Dec;12(4):502-7.

4. Alsadhan SA, Alsayari NF, Abuabat MF. Teachers' knowledge concerning dental trauma and its management in primary schools in Riyadh, Saudi Arabia. Int Dent J. 2018 Oct;68(5):306-13.

5. Bakarcic D, Hrvatin S, Maroevic M, Ivancic Jokic N. First Aid Management in Emergency Care of Dental Injuries - Knowledge among Teachers in Rijeka, Croatia. Acta Clin Croat. 2017 Mar;56(1):1106.

6. Jorge KO, Ramos-Jorge ML, de Toledo FF, Alves LC, Paiva SM, Zarzar PM. Knowledge of teachers and students in physical education's faculties regarding first-aid measures for tooth avulsion and replantation. Dent Traumatol. 2009 Oct;25(5):494-9.

7. Sae-Lim V, Lim LP. Dental trauma management awareness of Singapore pre-school teachers. Dent Traumatol. 2001 Apr;17(2):716.
8. de Oliveira DL, Ribeiro-Junior PD, Sbroggio AC, Dos Santos PG, Mori GG. Evaluation of Knowledge of Physical Education Students on Dental Trauma. Ann Maxillofac Surg. 2017 Jul-Dec;7(2):217-21.

9. Yigit Y, Helvacioglu-Yigit D, Kan B, Ilgen C, Yilmaz S. Dentofacial traumatic injuries: A survey of knowledge and attitudes among emergency medicine physicians in Turkey. Dent Traumatol. 2019 Feb;35(1):20-6.

10. Ivancic Jokic N, Bakarcic D, Grzic R, Majstorovic M, Sostarek M What general medicine students of University of Rijeka know about dental avulsion? Eur J Dent Educ. 2017 Nov;21(4):e131-4.

11. Al-Shamiri HM, Alaizari NA, Al-Maweri SA, Tarakji B. Knowledge and attitude of dental trauma among dental students in Saudi Arabia. Eur J Dent. 2015 Oct-Dec;9(4):518-22.

12. Malmgren B, Andreasen JO, Flores MT, Robertson A, DiAngelis AJ, Andersson L, et al. International Association of Dental Traumatology guidelines for the management of traumatic dental injuries: 3. Injuries in the primary dentition. Dent Traumatol. 2012 Jun;28(3):174-82.

13. Iyer SS, Panigrahi A, Sharma S. Knowledge and Awareness of First Aid of Avulsed Tooth among Physicians and Nurses of Hospital Emergency Department. J Pharm Bioallied Sci. 2017 AprJun;9(2):94-8.

14. Raoof M, Vakilian A, Kakoei S, Manochehrifar H, Mohammadaliza deh S. Should medical students be educated about dental trau- 
ma emergency management? A study of physicians and dentists in Kerman Province, Iran. J Dent Educ. 2013 Apr;77(4):494-501.

15. Raoof M, Zaherara F, Shokouhinejad N, Mohammadalizadeh S. Elementary school staff knowledge and attitude with regard to first-aid management of dental trauma in Iran: a basic premise for developing future intervention. Dent Traumatol. 2012 Dec;28(6):441-7.

16. Nikolic H, Ivancic Jokic N, Bakarcic D, Hrvatin S, Jakljevic N. Knowledge about emergency procedure in case of dental trauma among paediatricians in Croatia. Eur J Paediatr Dent. 2018 Dec;19(4):277-281.

17. Antunes LA, Rodrigues AS, Martins AM, Cardoso ES, Homsi N, Antunes LS. Traumatic dental injury in permanent teeth: knowledge and management in a group of Brazilian school teachers. Dent Traumatol. 2016 Aug;32(4):269-73.

18. Sen Yavuz B, Sadikoglu S, Sezer B, Toumba J, Kargul B. An Assessment of the Knowledge of Dentists on the Emergency Management of Avulsed Teeth. Acta Stomatol Croat. 2020 Jun;54(2):136 46.

19. Qazi SR, Nasir KS. First-aid knowledge about tooth avulsion among dentists, doctors and lay people. Dent Traumatol. 2009 Jun;25(3):295-9.

20. Abu-Dawoud M, Al-Enezi B, Andersson L. Knowledge of emergency management of avulsed teeth among young physicians and dentists. Dent Traumatol. 2007 Dec;23(6):348-55.

21. Holan G, Shmueli Y. Knowledge of physicians in hospital emergency rooms in Israel on their role in cases of avulsion of permanent incisors. Int J Paediatr Dent. 2003 Jan;13(1):13-9.

22. Lin S, Levin L, Emodi O, Fuss Z, Peled M. Physician and emergency medical technicians' knowledge and experience regarding dental trauma. Dent Traumatol. 2006 Jun;22(3):124-6.

23. Tzimpoulas N, Markou M, Zioutis V, Tzanetakis GN. A questionnaire-based survey for the evaluation of the knowledge level of primary school teachers on first-aid management of traumatic dental injuries in Athens, Greece. Dent Traumatol. 2020 Feb;36(1):41-50.

24. Panzarini SR, Pedrini D, Brandini DA, Poi WR, Santos MF, Correa $\mathrm{IP}$, et al. Physical education undergraduates and dental trauma knowledge. Dent Traumatol. 2005 Dec;21(6):324-8
25. Nashine N, Bansal A, Tyagi P, Jain M, Jain A, Tiwari U. Comparison and Evaluation of Attitude and Knowledge Towards the Management of Dental Injury in School Teachers Before and After Oral Health Education. Int J Clin Pediatr Dent. 2018 SepOct;11(5):425-9.

26. Razeghi S, Mohebbi SZ, Gholami M, Mashayekhi M, Maraghehpour B, Rahnama E. Effect of two educational interventions on primary school teachers' knowledge and self-reported practice regarding emergency management of traumatic dental injuries. BMC Oral Health. 2019;19(1):130.

27. Frujeri Mde L, Costa ED, Jr. Effect of a single dental health education on the management of permanent avulsed teeth by different groups of professionals. Dent Traumatol. 2009 Jun;25(3):262-71.

28. Kaul R, Jain P, Saha N, Goswami S, Mukhopadhyay S, Saha S, et al. Evaluation of knowledge, awareness, and attitude toward emergency dental trauma management among the school teachers of Kolkata. Indian J Dent Res. 2017 Nov-Dec;28(6):595-603.

29. Awad MA, AlHammadi E, Malalla M, Maklai Z, Tariq A, Al-Ali B, et al. Assessment of Elementary School Teachers' Level of Knowledge and Attitude regarding Traumatic Dental Injuries in the United Arab Emirates. Int J Dent. 2017;2017:1025324.

30. Prasanna S, Giriraju A, Narayan NL. Knowledge and Attitude of Primary School Teachers toward Tooth Avulsion and Dental First Aid in Davangere City: A Cross-sectional Survey. Int J Clin Pediatr Dent. 2011 Sep-Dec;4(3):203-6.

31. Young C, Wong KY, Cheung LK. Emergency management of dental trauma: knowledge of Hong Kong primary and secondary school teachers. Hong Kong Med J. 2012 Oct;18(5):362-70.

32. Fujita Y, Shiono Y, Maki K. Knowledge of emergency management of avulsed tooth among Japanese dental students. BMC Oral Health. 2014 Apr 8;14:34.

33. Alyasi M, Al Halabi M, Hussein I, Khamis AH, Kowash M. Dentists' knowledge of the guidelines of traumatic dental injuries in the United Arab Emirates. Eur J Paediatr Dent. 2018 Dec;19(4):271276.

34. Zaleckienè V, Pečiulienè V, Brukienè V, Jakaitienè A, Aleksejūnienė J, Zaleckas L. Knowledge about traumatic dental injuries in the permanent dentition: A survey of Lithuanian dentists. Dent Traumatol. 2018 Apr;34(2):100-6. 